\title{
Preparation of Syngeneic Tumor Regressor Serum Reactive with the Unique Determinants of the Abelson Murine Leukemia Virus-Encoded P120 Protein at the Cell Surface
}

\author{
O. N. WITTE, ${ }^{1}$ N. ROSENBERG, ${ }^{2}$ AND D. BALTIMORE ${ }^{1 *}$ \\ Department of Biology and Center for Cancer Research, Massachusetts Institute of Technology, Cambridge, \\ Massachusetts 02139, ${ }^{1}$ and Cancer Research Center, Tufts University School of Medicine, Boston, \\ Massachusetts $02111^{2}$
}

Received for publication 30 March 1979

\begin{abstract}
Antisera reactive with the Abelson murine leukemia virus (A-MuLV)-specified $\mathrm{P} 120$ (anti-AbT sera) were produced in C57L/J mice. Of many strains tested, only $\mathrm{C57L} / \mathrm{J}$ reproducibly rejected syngeneic $\mathrm{A}-\mathrm{MuLV}$-induced tumor cells; after multiple immunizations their sera would immunoprecipitate both P120 and Moloney-MuLV (M-MuLV) proteins. Using labeled A-MuLV-induced nonproducer cells, only P120 could be detected by anti-AbT sera, suggesting that it may be the only A-MuLV-specified protein. Reactivity of anti-AbT sera with P120 was not blocked by M-MuLV virion proteins, implying that the sera recognize a portion of P120 that is not homologous to any M-MuLV product. Anti-AbT sera stained the surface of live, A-MuLV-transformed nonproducer cells in a two-stage immunofluorescence assay, and such staining was not blocked by M-MuLV protein. Also, intact A-MuLV-transformed cells absorbed much of the reactivity of certain anti-AbT sera for P120. Thus a portion of P120 appears to be exposed on the surface of transformed cells. P120 lacks detectable carbohydrate, is not affected by endoglycosidase $\mathrm{H}$, and cannot be labeled by lactoperoxidase-catalyzed iodination. Thus P120 is an unusual surface protein.
\end{abstract}

Abelson murine leukemia virus (A-MuLV) is a defective, transforming retrovirus isolated from a corticosteroid-treated BALB/c mouse that had been inoculated with the replicationcompetent virus, Moloney MuLV (M-MuLV) (1). A-MuLV has unique biological and biochemical properties that distinguish it from its parent virus. Most importantly, A-MuLV transforms a different class of hematopoietic target cells from M-MuLV (9-11, 13, 17, 18, 21-23), and A-MuLV is capable of transforming fibroblastic cells (19). A-MuLV, like other defective, transforming retroviruses, requires a helper virus (like M-MuLV) to provide its structural proteins and its enzymatic functions for replication $(5,27)$.

A-MuLV RNA is 5,600 bases long and shares sequence homology with $\mathrm{M}-\mathrm{MuLV}$ at its $5^{\prime}$ and $3^{\prime}$ ends (A. Shields, Ph.D. thesis, Massachusetts Institute of Technology, Cambridge, 1979). A single stretch of 3,600 nucleotides of sequence not derived from M-MuLV fills the center of the A-MuLV genome.

The only known protein encoded by the AMuLV genome is one of 120,000 molecular weight called P120 $(14,29)$. This protein contains serological determinants of the M-MuLV amino-terminal gag gene products-p15, p12, and a portion of p30-fused to a region of approximately 90,000 molecular weight derived from the $\mathrm{A}-\mathrm{MuLV}$ unique sequences.

In an attempt to make an antiserum that might recognize the unique (non-M-MuLV) determinants on the A-MuLV P120, we have used the one case we could find in which mice would reproducibly reject a syngeneic A-MuLV-transformed cell line. Because xenogeneic sera from animals that have rejected Rous sarcoma virusinduced tumors have been so useful in defining the transforming protein of that virus $(3,12)$, it seemed possible that syngeneic immunization with A-MuLV-induced tumors would be similarly useful. Risser et al. (16) have already shown the utility of this approach in their description of an A-MuLV-related cell surface antigen detected by antibody-mediated cytotoxity. We have prepared sera that precipitate $\mathrm{P} 120$ via its unique determinants and have used the sera in a two-stage immunofluorescence assay to detect an A-MuLV-specific cell surface antigen.

\section{MATERIALS AND METHODS}

Cell lines. A-MuLV-transformed BALB/c lymphoid cell lines $2 \mathrm{M} 3$ (nonproducer) and 2M3/M (producer of A-MuLV and M-MuLV), C57L/J lymphoid 
cell line $\mathrm{L} 1$ and subclone L1-2, nonproducer NIH mouse fibroblast line $A 2$, and rat cell line Ab-NRK have been previously described $(17,29)$.

Cell labeling and immunoprecipitation. All radioactive chemicals were purchased from New England Nuclear Corp., Boston, Mass. Cells were labeled with $\left[{ }^{35} \mathrm{~S}\right]$ methionine $(50 \mu \mathrm{Ci} / \mathrm{ml})$ or $\left[{ }^{3} \mathrm{H}\right]$ leucine $(200$ $\mu \mathrm{Ci} / \mathrm{ml}$ ) in medium containing $1 / 100$ the normal methionine or $1 / 50$ the normal leucine concentration, respectively. Cells were pulse-labeled $(30 \mathrm{~min})$ with ${ }^{14} \mathrm{C}$-mixed amino acids $(25 \mu \mathrm{Ci} / \mathrm{ml})$ in balanced salt solution with glucose or were labeled in complete medium with $\mathrm{D}-\left[{ }^{3} \mathrm{H}\right]$ glucosamine at $100 \mu \mathrm{Ci} / \mathrm{ml}$.

Cells were iodinated by two techniques. Lactoperoxidase-catalyzed iodination at room temperature was performed as previously described (30) employing 500 $\mu \mathrm{Ci}$ of $\mathrm{Na}^{125} \mathrm{I}$ per $10^{7}$ cells, with $50 \mu \mathrm{g}$ of lactoperoxidase (Calbiochem, grade B). Specific activities were $10^{7}$ to $3 \times 10^{7} \mathrm{cpm} / 10^{7}$ cells. Iodination by ${ }^{125} \mathrm{I}$-labeled Bolton Hunter reagent was performed at $0^{\circ} \mathrm{C}$. Cells $\left(10^{5}\right.$ to 2 $\times 10^{7}$ ) were washed with phosphate-buffered saline (pH 7.5), then resuspended in $1 \mathrm{ml}$ of phosphatebuffered saline with 50 to $75 \mu \mathrm{Ci}$ of Bolton-Hunter reagent for $30 \mathrm{~min}$. Cells were washed with phosphatebuffered saline, and excess reagent was quenched with glycine. Specific activities were $3 \times 10^{7}$ to $7 \times 10^{7} \mathrm{cpm} /$ $10^{7}$ cells.

Labeled cells were extracted and clarified for immunoprecipitation as previously described $(28,29)$. Routinely, $10^{7}$ labeled cells were extracted into $5 \mathrm{ml}$ of lysis buffer $\left(10 \mathrm{mM} \mathrm{NaH} \mathrm{PO}_{4}-\mathrm{Na}_{2} \mathrm{HPO}_{4}, \mathrm{pH} 7.5 ; 100\right.$ $\mathrm{mM} \mathrm{NaCl} ; 1 \%$ Triton $\mathrm{X}-100 ; 0.5 \%$ sodium deoxycholate; $0.1 \%$ sodium dodecyl sulfate) at $0^{\circ} \mathrm{C}$ and clarified at $150,000 \times g$ for $3 \mathrm{~h}$. One-milliliter fractions were precipitated with normal or immune serum. Samples were analyzed by electrophoresis through $10 \%$ polyacrylamide-sodium dodecyl sulfate gels developed by fluorography $(2,7,8)$. Films were exposed for 2 to 3 days.

Antisera used included rabbit anti-M-MuLV reverse transcriptase/p15, rabbit anti-M-MuLV gp70, and goat anti-M-MuLV virions, which have been previously described $(28,29)$.

Membrane immunofluorescence. All sera and media employed were filtered through $0.2-\mu \mathrm{m}$ filters or clarified at $100,000 \times g$ for $2 \mathrm{~h}$ before use to remove aggregates. Viable cells $\left(2 \times 10^{6}\right)$ were washed twice in RPMI-1640 with $10 \%$ heat-inactivated fetal calf serum and suspended at $0^{\circ} \mathrm{C}$ in $50 \mu$ l of normal serum or antiserum for $45 \mathrm{~min}$. Cells were washed by sedimentation through heat-inactivated fetal calf serum, resuspended, and washed with RPMI-10\% heat-inactivated fetal calf serum. Pretitrated dilutions of fluorescein-conjugated second-stage antibody (goat antimouse immunoglobulin $\mathrm{G}$ or goat anti-rabbit immunoglobulin G; Meloy Labs, Springfield, Va.) were mixed with cells for $45 \mathrm{~min}$ at $0^{\circ} \mathrm{C}$. The cells were washed as above and suspended in RPMI-10\% heatinactivated fetal calf serum to view as wet mounts or alternatively, in phosphate-buffered saline-50\% heatinactivated fetal calf serum to prepare air-dried, methanol-fixed smears. Slides were viewed with a Leitz Ortholux microscope, and photographs were taken on Kodak Tri-X film. All cell counts represented averages of two separate experiments counting 100 cells each.
Sepharose-coupled M-MuLV virion proteins. A 40-mg sample of unlabeled M-MuLV protein was derived from virions that were purified from culture supernatant fluids by two cycles of sucrose gradient centrifugation in the MIT Cell Culture Center. The virions were lysed with $5 \%$ Triton X-100-0.5 M NaCl, dialyzed to $\mathrm{pH} 8.5(100 \mathrm{mM} \mathrm{NaHCO})$, and coupled with $4 \mathrm{~g}$ of freeze-dried $\mathrm{CNBr}$-activated Sepharose $4 \mathrm{~B}$ (Pharmacia Fine Chemical Corp.) overnight at $4^{\circ} \mathrm{C}$. ${ }^{35}$ S]methionine-labeled M-MuLV $\left(10^{6} \mathrm{cpm}\right)$ was added as a tracer. After washing, the final coupled protein was estimated at $2.5 \mathrm{mg} / \mathrm{ml}$ of swollen resin.

\section{RESULTS}

Production of an antiserum reactive with A-MuLV-specified P120 (anti-AbT). To develop a syngeneic regressor system for production of anti-A-MuLV sera, various cell line and mouse strain combinations were examined. The approach used involved injecting mice with live, in vitro-derived transformed lymphoid cells, monitoring the mice for tumor formation and subsequent rejection, and then challenging them with increasing cell doses. Activity against AMuLV-specified proteins was determined by direct immunoprecipitation (see below).

Initially, 15 independently derived A-MuLVtransformed lymphoid cell lines of BALB/c origin were injected into syngeneic mice. Progressive, disseminated tumors developed in the majority of the mice, a finding consistent with earlier reports $(10,17,21)$. Use of low doses $\left(10^{3}\right.$ cells per mouse) of nonproducer cells given intraperitoneally resulted in $100 \%$ mortality in 3 weeks. When low doses of live or mitomycin Ctreated cells (injected subcutaneously) did not kill all of the animals, the survivors failed to reject increased doses of cells and did not produce a demonstrable response to A-MuLV proteins. BALB/c-derived $\mathrm{H}-2^{\mathrm{k}}$ congenic mice rejected high doses $\left(>10^{6}\right.$ cells per mouse) of BALB/c-derived nonproducer cells but did not respond to A-MuLV proteins.

Because the BALB/c system proved unsuccessful, lymphoid cell lines derived from SWR/ $\mathrm{J}, \mathrm{C} 57 \mathrm{BRcd} / \mathrm{J}, \mathrm{C} 57 \mathrm{BL} 6 / \mathrm{J}$, and C57L/J mice were examined. Groups of 20 mice were injected with two SWR/J and one C57BRcd/J-derived cell line, and all of the mice tested succumbed to the initial inoculum. Even doses of $10^{3}$ cells of the C57BRcd/J nonproducer cell line BR48 killed most of the test animals in 3 to 4 weeks. C57BL6 mice, used to produce anti-Abelson sera by another laboratory (16), failed to reject a dose of $10^{5}$ live syngeneic cells given subcutaneously. Forty percent $(2 / 5)$ of the animals injected intraperitoneally with $10^{5}$ cells survived this dose and two subsequent challenges. The serum from these mice, however, reacted predominantly with helper virus-specified struc- 
tural proteins (data not shown).

With C57L/J mice we were finally successful. C57L/J mice were injected subcutaneously with either a focus-derived syngeneic cell line designated L1 or a subclone of this cell line, L1-2, at doses of $10^{5}$ or $5 \times 10^{5}$ live cells per animal. Eighty-five percent $(12 / 14)$ of the L1-injected mice survived the initial dose, and $100 \%(5 / 5)$ of the initial L1-2 group and $90 \%(27 / 30)$ of a larger second group survived. The initial inoculum grew in the mice as evidenced by the development of small (1- to $3-\mathrm{cm}$ ) nodules at the injection site about 1 week postinoculation; these growths disappeared by 2 to 2.5 weeks postinjection. Animals surviving the initial cell dose rejected subsequent intraperitoneal challenges of up to $10^{7}$ cells per mouse.

Specificity of anti-Abelson tumor sera (anti-AbT): reactivity with P120. Serum samples collected from C57L/J animals 10 to 14 days after the second and subsequent tumor challenge doses were tested for their immunoprecipitation specificity. Extracts of 2M3/M cells (a BALB/c, A-MuLV-transformed, producer cell line) pulse labeled for $30 \mathrm{~min}$ with $\left[{ }^{35} \mathrm{~S}\right]$ methionine were used as the test antigen. This cell line expresses both the A-MuLV-encoded P120 and the major structural protein precursors of the helper virus (M-MuLV). Screening of serum samples of individual mice taken after the second tumor challenge showed that all animals had a response to the P120 protein of $\mathrm{A}-\mathrm{MuLV}$, but the intensity varied widely (Fig. 1). Animals numbered 1 to 12 were injected and boosted with cell line $\mathrm{L} 1$, and numbers 13 to 17 were injected with subclone L1-2. The presence of detectable antibody reactive to the M-MuLV core precursor (Pr65 ${ }^{\text {gag }}$ ) and envelope precursor (Pr80 ${ }^{e n v}$ ) varied but was more pronounced in the group injected with L1. During repeated cycles of immunization, these differences in precipitating antibody patterns were minimized and a common pattern of prominent response to $\mathrm{P} 120$ and $\mathrm{Pr} 80^{\text {env }}$ and weak or absent response to Pr65 ${ }^{\text {gag }}$ was found. Only antibody that could bind to the Staphylococcus aureus immune adsorbent was monitored in the above screenings, but subsequent testing of serum pools employing goat anti-mouse immunoglobulin in a two-stage precipitation assay did not reveal any additional specificities (data not shown). Tests with $\left[{ }^{35} \mathrm{~S}\right]$ methionine-labeled extracts of the L1 or L1-2 cell lines also did not reveal any additional specificities or unusual quantitative differences between these AMuLV-transformed cell lines and those of other strains (data not shown).

Lack of other A-MuLV-related products.

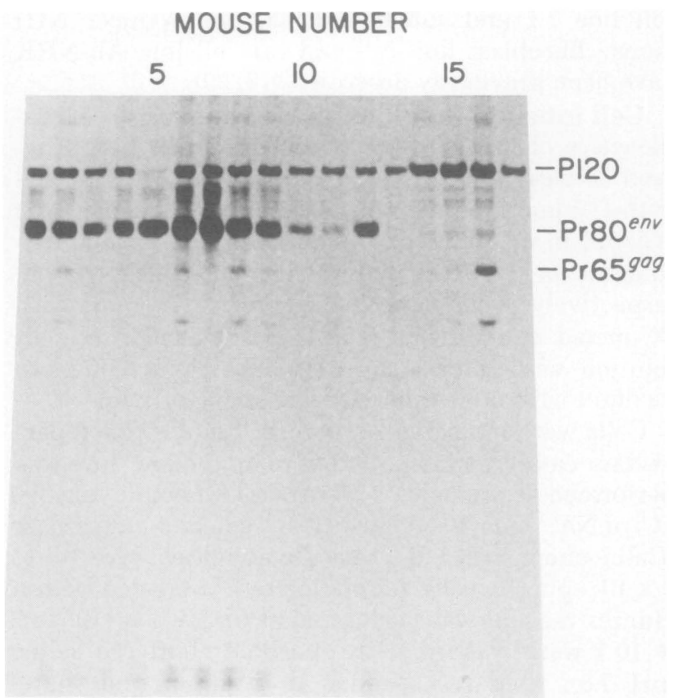

Fig. 1. Screening of anti-AbT sera from individual mice. Mice of the C57L/J strain were inoculated with viable cells of the in vitro-transformed clonal lymphoid cell line L1 (mice no. 1 to 12) or a subclone, L1-2 (mice no. 13 to 17). Serum was harvested 12 days after the second inoculation, and 2.5- $\mu$ l portions were tested by immunoprecipitation of extracts of $2 M 3 / M$ cells labeled for 30 min with $\left[{ }^{35} S\right]$ methionine. Precipitates were collected on $S$. aureus immunoadsorbent (7) and analyzed by electrophoresis through $10 \%$ polyacrylamide-sodium dodecyl sulfate gels (8) developed by fluorography (2).

To search for additional A-MuLV-specified proteins that might lack methionine, we labeled AMuLV-transformed cells with a variety of protein precursors, or by chemical iodination techniques, and used extracts of these labeled cells in direct immunoprecipitation assays with pools of anti-AbT serum. To simplify the analysis, we used A-MuLV-transformed, nonproducer cell lines, like $2 \mathrm{M} 3$, to direct attention to $\mathrm{A}-\mathrm{MuLV}$ genome expression rather than that of the $\mathbf{M}$ MuLV helper virus. When $2 \mathrm{M} 3$ cells were pulselabeled $(1 \mathrm{~h})$ with $\left[{ }^{3} \mathrm{H}\right]$ leucine (Fig. $\left.2 \mathrm{~A}\right)$ or ${ }^{14} \mathrm{C}$ mixed amino acids (Fig. 2C), or labeled for $18 \mathrm{~h}$ with $\left[{ }^{3} \mathrm{H}\right]$ leucine (Fig. $2 \mathrm{~B}$ ), the only reproducibly immunoprecipitable protein was the $\mathrm{P} 120$ protein. Similar tests were done using mouse and rat A-MuLV-transformed nonproducer fibroblast cultures with the same results.

To further evaluate the specificities of the anti-AbT serum, and to search for putative AMuLV-related proteins that could have extremely low synthetic rates but be stable enough to accumulate within the cells, we used chemical iodination techniques. Lactoperoxidase-catalyzed iodination labels available tyrosine and 


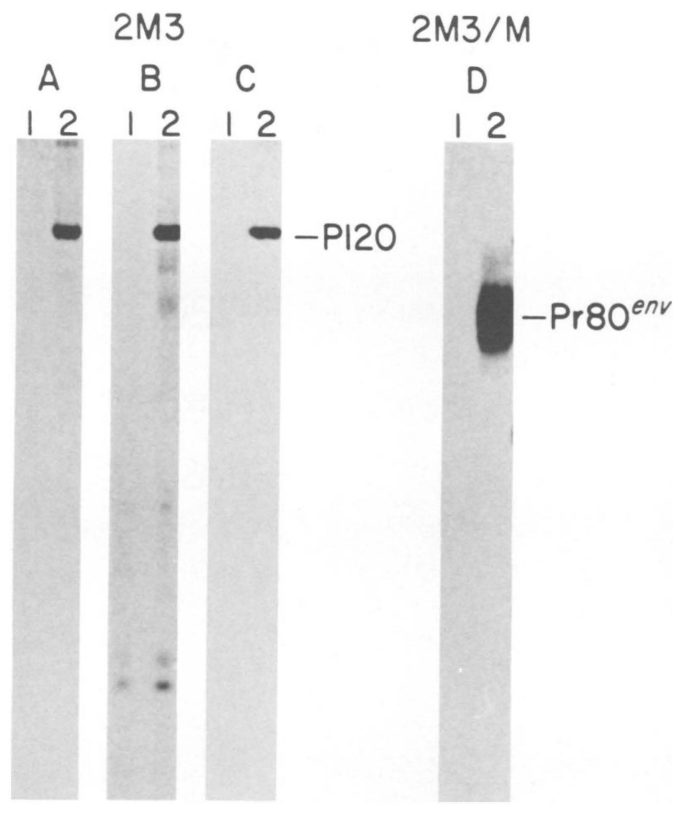

Fig. 2. Specificities of anti-AbT serum tested on metabolically labeled cells. Normal mouse serum (lane 1) was compared to pooled anti-AbT serum (lane 2) for immunoprecipitation of proteins from $(A)$ $2 M 3$ cells labeled for $1 \mathrm{~h}$ with $\left[{ }^{3} \mathrm{H}\right]$ leucine; (B) $2 M 3$ cells labeled for $18 \mathrm{~h}$ with $\left[{ }^{3} \mathrm{H}\right]$ leucine; (C) $2 \mathrm{M} 3$ cells labeled for $1 \mathrm{~h}$ with ${ }^{14} \mathrm{C}$-mixed amino acids; or (D) $2 M 3 / M$ cells labeled for $5 \mathrm{~h}$ with $\mathrm{D} \cdot\left[^{3} \mathrm{H}\right]$ glucosamine. Samples were analyzed as described in Fig. 1.

histidine residues on peripheral membrane proteins. It has been used to label the MuLV env gene product, gp70, on the virion and cell surface (6, 30, 31). A-MuLV-transformed nonproducer line 2M3 (Fig. 3, lane A) and its M-MuLV-superinfected derivative $2 \mathrm{M} 3 / \mathrm{M}$ (Fig. 3, lane B) were labeled to high specific activity, and extracts were immunoprecipitated with anti-AbT serum. Only gp70 on the producer cell line 2M3/ $M$ was detected. Neither P120 or other potential A-MuLV proteins were labeled.

We extended our studies to a reagent that could penetrate into cells and label proteinsthe Bolton-Hunter reagent. It reacts rapidly with free amino groups and will function at $\mathrm{pH}$ 7.5 and low temperature. Intact 2M3 (Fig. 3C) and $2 \mathrm{M} 3 / \mathrm{M}$ (Fig. 3D) cells were labeled at $0^{\circ} \mathrm{C}$ with ${ }^{125}$ I-labeled Bolton-Hunter reagent, washed, and extracted for immunoprecipitation with anti-AbT serum. P120 was now labeled in both cell lines, as were the Pr80 $0^{\text {env }}$ and Pr65 gag precursors in the $2 \mathrm{M} 3 / \mathrm{M}$ cells. No additional AMuLV-related proteins were detected.

These studies do not rule out the possibility of an additional protein encoded by A-MuLV;

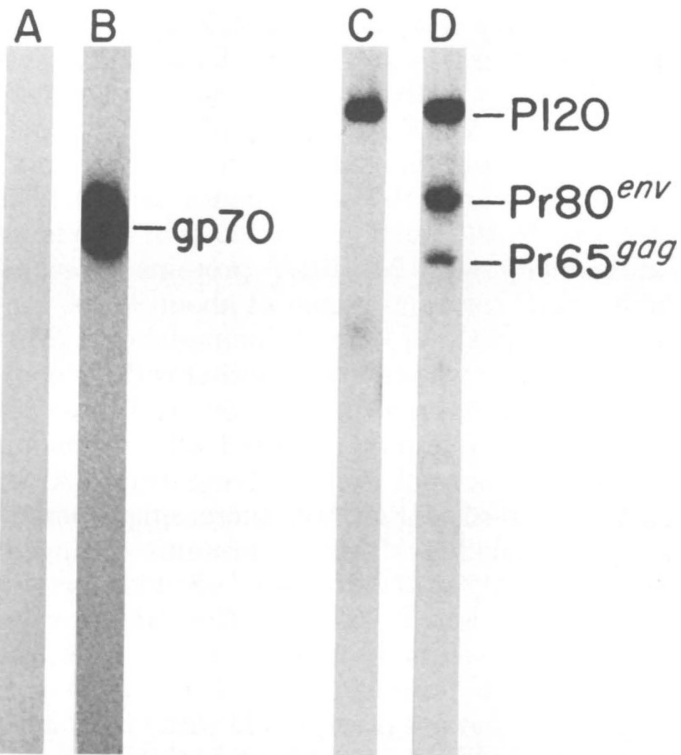

Fig. 3. Specificities of anti-AbT serum tested on chemically iodinated cells. Viable $2 \mathrm{M} 3$ cells (A) or $2 M 3 / M$ cells $(B)$ were labeled with $N a^{125} I$ by the lactoperoxidase technique, or, alternatively, $2 M 3$ cells $(C)$ and $2 M 3 / M$ cells $(D)$ were labeled with the ${ }^{125}$ I-labeled Bolton-Hunter reagent. Extracts were immunoprecipitated with anti-AbT serum, and precipitates were analyzed as described in Fig. 1.

they show, however, that the anti-tumor antiserum we have prepared strongly precipitates $\mathrm{P} 120$ and that P120 is the only A-MuLV-specific protein detected even when various metabolic and chemical labels are used.

Lack of carbohydrate on P120. In several attempts, we have been unable to label P120 or any additional A-MuLV-related protein with sugar precursors of glycoproteins. When 2M3/ $M$ cells (the nonproducer line superinfected with M-MuLV) were labeled with $D-\left[{ }^{3} \mathrm{H}\right]$ glucosamine for $5 \mathrm{~h}$ (Fig. 2D), the $\operatorname{Pr} 80^{e n v}$ precursor was heavily labeled but P120 was not labeled. The faint band(s) at 90,000 to 95,000 molecular weight is the glycosylated form of the M-MuLV gag gene (gp90 gag) similar to that described for other ecotropic MuLV strains (26). In other experiments, $\left[{ }^{3} \mathrm{H}\right]$ mannose did not label $\mathrm{P} 120$. Furthermore, P120 pulse-labeled with $\left[{ }^{35}\right.$ S $]$ methionine and isolated by immunoprecipitation was not sensitive to the action of endo- $\beta$ - $\mathrm{N}$-acetylglucosaminidase $H$, an enzyme that cleaves the high mannose structures from recently made glycoproteins and thus markedly changes their electrophoretic mobility $(25,32)$. Hence, no detectable fraction of P120 undergoes carbohydrate addition. 
Reactivity with the A-MuLV-specific portion of P120. Because P120 shares serological determinants with the N-terminal gag gene products (p15, p12, and part of p30), we performed competition experiments to determine whether the anti-AbT serum contains antibodies reactive to the portion of $\mathrm{P} 120$ that shares no antigenicity with M-MuLV proteins (presumably the C-terminal region of about 90,000 molecular weight). A $\left[{ }^{35} \mathrm{~S}\right]$ methionine-labeled $2 \mathrm{M} 3$ / $M$ cell extract was incubated either without competing protein, or with 50 or $150 \mu \mathrm{g}$ of lysed MMuLV virions, and precipitated with a constant amount of normal mouse serum (Fig. 4A) or anti-AbT serum (Fig. 4B). Increasing amounts of the unlabeled M-MuLV proteins competed out the ability of the anti-AbT serum to precipitate $\operatorname{Pr} 80^{e n v}$ and Pr65 gag, but the P120 precipitation was essentially unaffected. We have also been able to proteolytically cleave P120 into fragments that are precipitable with either antigag gene product reagents or anti-AbT serum but not both (unpublished data).

A-MuLV cell surface antigen. To test whether anti-AbT serum could react with a cell surface antigen on A-MuLV-transformed cells, we have used a two-stage immunofluorescence procedure with intact viable cells as our test antigen. Sera with specificity for the helper virus M-MuLV gene products gp70, p30, and p15 as well as anti-AbT serum have been tested on several A-MuLV-transformed nonproducer cell lines as well as on producer cells containing both the A-MuLV and M-MuLV gene products (summarized in Table 1).

Only the anti-AbT serum was able to stain the cell membrane of A-MuLV-transformed nonproducer lines such as $2 \mathrm{M} 3$ (Fig. 5). Sera with specificity to the gag gene-related portion of P120, like anti-p15 and anti-p30, although able to precipitate P120 from lysed cells (29), could not stain the surface of viable cells. $\mathrm{Ab}$ sorption of anti-AbT serum with M-MuLV proteins coupled to Sepharose did not diminish the staining on A-MuLV-transformed nonproducer cells.

Absorption of anti-AbT serum with one AMuLV-transformed nonproducer cell line, however, removed the ability to stain a second AMuLV nonproducer cell line. A 1:20 dilution of the pool of anti-AbT serum used in Fig. 5 was absorbed with intact, viable A2 cells (a transformed NIH/3T3 fibroblast nonproducer). The absorbed serum and a control dilution were clarified and assayed for their ability to stain the surface of $2 \mathrm{M} 3$ cells (a BALB/c lymphoid nonproducer cell) and 2M3/M (the M-MuLV-superinfected counterpart; Fig. 6A and B). The ab-

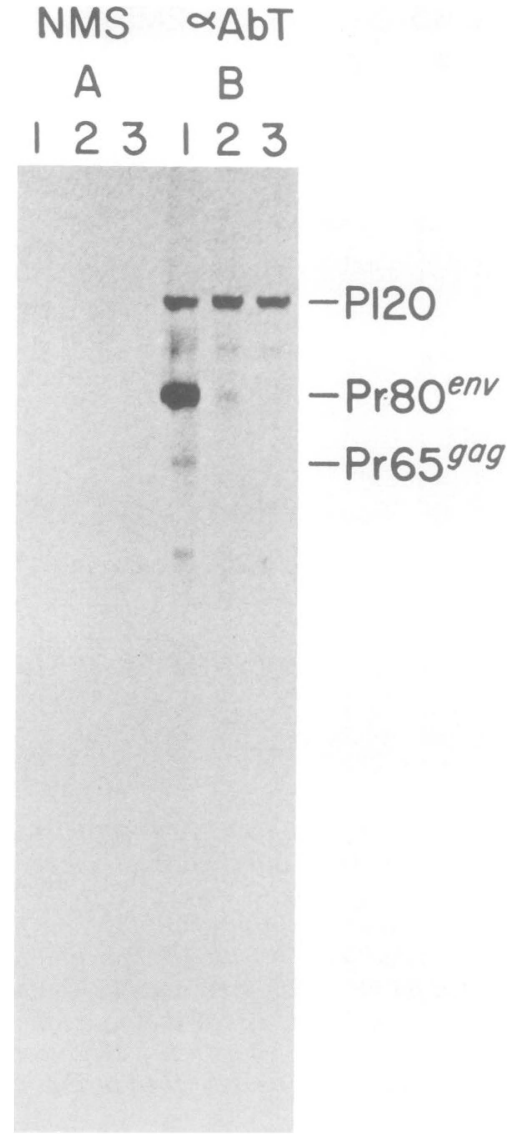

Fig. 4. Demonstration of activity for the unique portion of P120 in anti-AbT serum. Extracts of 2M3/ $M$ cells labeled for 30 min with $\left[{ }^{35} S\right]$ methionine; cells were immunoprecipitated with $2.5 \mu l$ of (A) normal mouse serum (NMS) or (B) anti-Abelson tumor serum $(\alpha A b T)$. Lane 1 had no competing protein; lane 2 had $50 \mu \mathrm{g}$ and lane 3 had $150 \mu \mathrm{g}$ of $M-M u L V$ virion proteins included in the lysate. Samples were collected and analyzed as described in Fig. 1.

sorbed serum was markedly reduced in its ability to stain the nonproducer cell line $2 \mathrm{M} 3$, which expresses only P120, but retained the ability to stain the M-MuLV-superinfected 2M3/M line, which also expresses at the cell membrane the M-MuLV env gene products gp70 and p15E. This difference was reflected in residual immunoprecipitation capability of the control and absorbed anti-AbT serum. Because A2 cells do not express the M-MuLV env gene, after absorption with these cells there was no detectable difference in the ability of anti-AbT serum to precipitate the $\operatorname{Pr} 80^{\text {env }}$ precursor from $2 \mathrm{M} 3 / \mathrm{M}$ cells (Fig. 6C). Absorption with A2 cells, however, caused a marked decrease in precipitating antibody for P120; after absorption only 10 to $20 \%$ 
TABLE 1. Cell surface fluorescence on A-MuLV-transformed cells ${ }^{a}$

\begin{tabular}{|c|c|c|c|c|}
\hline \multirow{2}{*}{ Serum } & \multicolumn{4}{|c|}{ Percent of fluorescent cells in cell line ${ }^{b}$} \\
\hline & A2 & AbNRK & $2 \mathrm{M} 3$ & 2M3/M \\
\hline Normal mouse serum & $<1$ & $<1$ & $<1$ & $<1$ \\
\hline Anti-AbT & $>95(++)$ & $>95(+++)$ & $>95(+++)$ & $>95(++++)$ \\
\hline $\begin{array}{l}\text { Anti-AbT absorbed with } \\
\text { M-MuLV proteins cou- } \\
\text { pled to Sepharose }\end{array}$ & $>95(++)$ & $>95(++)$ & $>95(+++)$ & $>95(+++)$ \\
\hline Normal rabbit serum & $<1$ & $<1$ & $<1$ & $<1$ \\
\hline $\begin{array}{l}\text { Rabbit anti-M-MuLV p15/ } \\
\text { reverse transcriptase }\end{array}$ & $<1$ & $\mathrm{NT}^{d}$ & $2(+)$ & $75(+)$ \\
\hline Rabbit anti-M-MuLV p30 & $<1$ & NT & $<1$ & $>95(++)$ \\
\hline Rabbit anti-M-MuLV gp70 & $<1$ & $<1$ & $<1$ & $>95(++++)$ \\
\hline
\end{tabular}

${ }^{a}$ Viable cells $\left(10^{6}\right.$ to $\left.2 \times 10^{6}\right)$ were stained for cell surface antigens in suspension at $4^{\circ} \mathrm{C}$ with $50 \mu \mathrm{l}$ of normal or immune serum at a final 1:20 dilution. Fluoresceinated goat anti-mouse or goat anti-rabbit immunoglobulin G (Meloy Labs) at 1:15 and 1:40 dilutions, respectively, were used for the second stage. Wet mounts and airdried, methanol-fixed smears were counted (minimum of 100 cells each) to determine a percentage of positive staining. A subjective quantitation of + (dull) to ++++ (very bright) is shown.

${ }^{b}$ Cell lines: A2, NIH/3T3 nonproducer; AbNRK, normal rat kidney nonproducer; 2M3, BALB/c lymphoid nonproducer; $2 \mathrm{M} 3 / \mathrm{M}, 2 \mathrm{M} 3$ superinfected with $\mathrm{M}-\mathrm{MuLV}$.

c A 1-ml sample of 1:10-diluted anti-AbT was mixed with $2 \mathrm{ml}$ of wet packed Sepharose $2 \mathrm{~B}$ coupled with lysed M-MuLV proteins (2.5 mg of final protein bound per $\mathrm{ml}$ of Sepharose) for $6 \mathrm{~h}$ at $4^{\circ} \mathrm{C}$. The serum was recovered by centrifugation and reclarified before use.

of the precipitating activity for $\mathrm{P} 120$ was left in different pools (the residual P120 in lane 3, Fig. $6 \mathrm{C}$, is not evident in the print but was detectable on the autoradiogram). Therefore, a variable portion of the antibody to $\mathrm{P} 120$ may be reactive with determinants that are not accessible at the cell surface, but the majority could be absorbed by live cells. Similar absorption experiments using M-MuLV-infected NIH/3T3 cells or $M$ MuLV-infected Moloney sarcoma virus-transformed cells did not remove anti-P120 activity from the anti-AbT serum.

In separate experiments (data not shown), we found that P120 in intact cells was resistant to digestion with the proteases trypsin and chymotrypsin under conditions that previously were shown to remove peripheral proteins like gp70 (30). Such protease treatment did not diminish the ability of anti-AbT serum to stain A-MuLVtransformed cells.

Thus, it is likely that $\mathrm{P} 120$, or perhaps a fraction of the P120 molecules, exposes a portion of its 90,000-molecular weight unique region above the cell membrane but that other regions of the molecule, including the gag gene-related amino terminus, are buried in or beneath the lipid bilayer and not accessible to antibody molecules. The external region is not, however, detectably labeled by lactoperoxidase-catalyzed iodination and is not as protease sensitive as a peripheral membrane protein like gp70.

\section{DISCUSSION}

In the process of rejecting syngeneic tumors caused by $\mathrm{A}-\mathrm{MuLV}$-transformed cells, C57L/J mice make a humoral antibody response to the A-MuLV-specified P120 protein. No other AMuLV-specific protein is detected by such sera, and much of the antibody is directed to the AMuLV-specific region of P120. The serum detects cell surface antigen by live-cell staining in a two-stage immunofluorescence test. Because $\mathrm{P} 120$ is the only A-MuLV protein reactive with the serum, the results imply that at least part of the A-MuLV-specific region of $\mathrm{P} 120$ is exposed on the cell surface. The ability of intact cells to absorb much of the reactivity to $\mathrm{P} 120$ also argues that the protein is partly exposed on the cell surface.

P120 is not, however, a classic cell surface protein. It does not detectably label with carbohydrate precursors, it is not labeled by lactoperoxidase-catalyzed iodination, it is not cleaved by mild external treatment of cells with protease, and its mobility is not affected by treatment with endoglycosidase $\mathrm{H}$. By contrast, gp70 of MuLV has readily detectable carbohydrate, is iodinated, and is cleaved by protease, and the electrophoretic mobility of its intracellular form is increased by endoglycosidase $\mathrm{H}$ treatment $(6$, 30-32). Many other peripheral membrane proteins also have this set of characteristics. No good model exists for a non-glycosylated protein that is exposed on the cell surface. It is significant, however, that the feline oncornavirus-associated cell membrane antigen (FOCMA) of feline sarcoma virus has many properties in common with the A-MuLV P120 $(20,24)$ and is not 

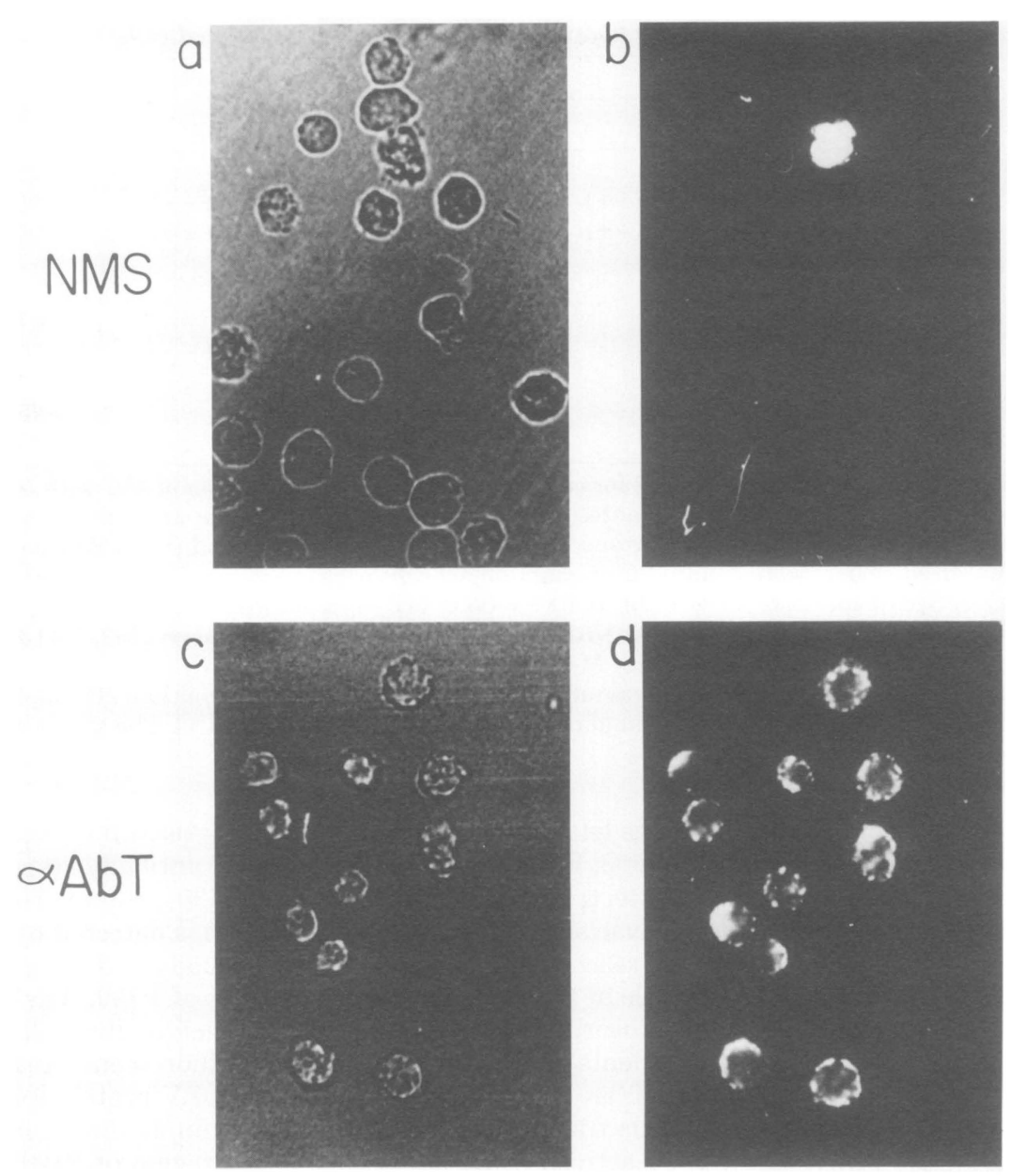

FIG. 5. Detection of an A-MuLV cell surface antigen by immunofluorescence. Intact, viable $2 M 3$ cells, a clonally derived $B A L B / c A-M u L V$-transformed lymphoid cell line, were tested in a two-stage immunofluorescence assay (see the text) employing normal mouse serum (NMS) or anti-AbT serum ( $\alpha A b T)$ at a final dilution of 1:20. After unbound antibody was washed away, fluoresceinated goat anti-mouse immunoglobulin $G$ at 1:15 final dilution was used and wet mounts were photographed. (a) Cells treated with normal mouse serum (NMS), phase contrast; (b) cells treated with normal mouse serum, fluorescence; (c) cells treated with anti-AbT serum, phase contrast; (d) cells treated with anti-AbT serum, fluorescence. Specific fluorescent staining in (d) is seen as small clusters or caps on the outer cell surface. Nonspecific homogeneous staining of a single dead cell is seen in (b).

glycosylated (Worley and Essex, personal communication). FOCMA is a surface antigen that is synthesized as part of a protein containing both gag determinants and a unique region. Also, a non-glycosylated adenovirus-simian virus 40 fusion protein is thought to be expressed at the cell surface (4) and may be important as a transplantation antigen.

It is curious that only C57L/J mice efficiently reject syngeneic A-MuLV-transformed cells. It is not known whether their ability to make antiAbT antibody is related to their rejection ability. To date we have found no unique feature of the
C57L/J strain or their A-MuLV-transformed cells that can explain the efficient tumor regression we have observed. Risser et al. (15) have described two genetic loci that control the relative resistance to $\mathrm{A}-\mathrm{MuLV}$ tumor induction. $\mathrm{C} 57 \mathrm{~L} / \mathrm{J}$ is among the resistant strains, but so are C57BR/cdJ and C57BL6/J, which we found much less efficient at rejecting syngeneic tumor challenge. C57L/J transformed cell lines showed no qualitative or quantitative difference in the level or pattern of expression of either the AMuLV P120 or M-MuLV proteins that we have yet discerned. 

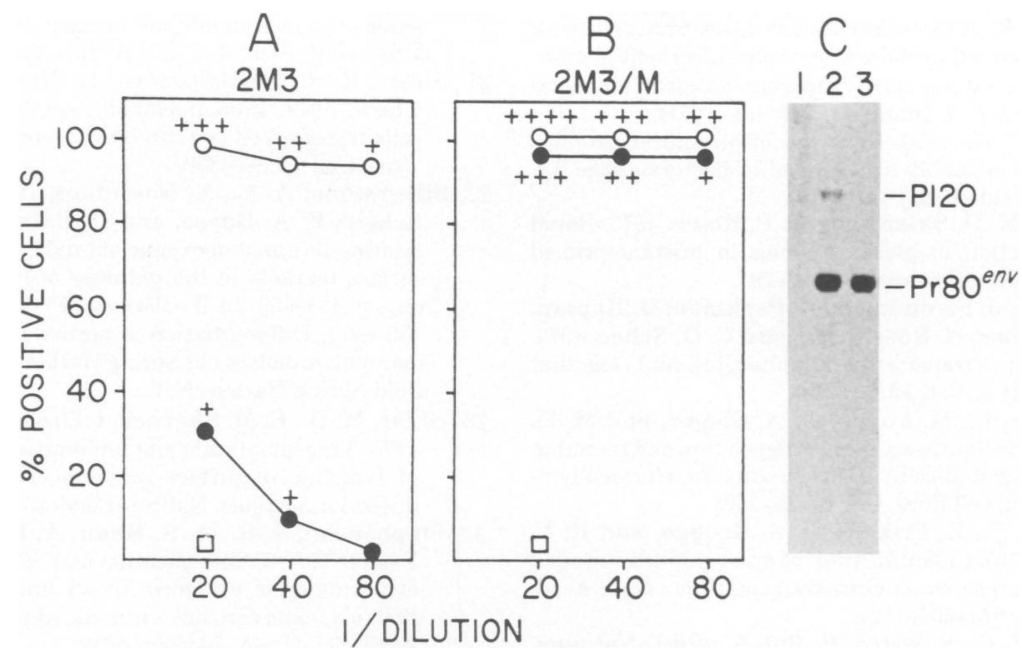

Fig. 6. Absorption of anti-AbT cell surface reactivity with transformed nonproducer cells. Dilutions of anti-AbT serum, unabsorbed control $(O)$ or absorbed with viable, intact A2 cells $(A-M u L V$-transformed NIH/ $3 T 3$ nonproducer cell line) (O) were used to surface stain viable $2 M 3$ cells $(A)$ and $2 M 3 / M$ cells (B). Absorption was carried out in three sequential cycles using $1 \mathrm{ml}$ of 1:20-diluted serum, $3 \times 10^{8}$ cells per cycle, and a 45min exposure at $0^{\circ} \mathrm{C}$. The percentage of positive cells and a visual estimate of average fluorescence intensity $(+=$ dull $;++++=$ very bright) were plotted and compared to staining with normal mouse serum $(\square) .(C)$ Immunoprecipitation of $2 M 3 / M$ cells labeled with $\left[{ }^{35} S\right]$ methionine for 30 min. Equivalent amounts of normal mouse serum (lane 1), control unabsorbed anti-AbT serum (lane 2), and absorbed anti-AbT serum (lane 3). Sample analysis was as described in Fig. 1.

The A-MuLV genome consists of a 5,600-base RNA of which about 3,600 bases are A-MuLV specific and 2,000 bases are derived from $M$ MuLV (Shields, Ph.D. thesis). P120 is encoded by about 2,700 bases of the A-MuLV-specific region, leaving 900 bases plus some of the $M$ MuLV sequences as regions that could potentially encode more A-MuLV-related proteins. Use of a second reading frame could make more coding potential available. It is not possible to exclude the existence of a second A-MuLV-specified protein, but no antiserum, whether anti$\mathrm{AbT}$ or anti-M-MuLV, has consistently revealed a second protein. Thus, it appears on present evidence that the A-MuLV genome encodes a single polypeptide and, assuming that $\mathrm{A}-\mathrm{MuLV}$ transforms through the action of a protein, $\mathrm{P} 120$ must be responsible for transforming cells. Whether the presence of part of P120 exposed on the cell surface is an aspect of its transforming activity remains to be demonstrated.

Risser et al. (16) have reported an Abelson tumor cell surface antigen detected by a cytotoxicity-absorption assay and have shown the presence of a cross-reacting antigen in normal lymphoid tissues (particularly bone marrow) of $\mathrm{BALB} / \mathrm{c}$ mice and closely related strains. Whether the antigenic specificity(ies) monitored in those studies is identical to the anti-P120 activity defined in the present analysis is not clear.

\section{ACKNOWLEDGMENTS}

We gratefully acknowledge the superb technical assistance of Dan Clark and Leslie Sun.

This work was supported by grant VC-4J from the American Cancer Society and Public Health Service grants CA14051 and CA-24220 from the National Cancer Institute. O.N.W. is a Helen Hay Whitney Postdoctoral Fellow. N.R. is a Research Scholar of the American Cancer Society, Massachusetts Division. D.B. is a Research Professor of the American Cancer Society.

\section{LITERATURE CITED}

1. Abelson, H. T., and L. S. Rabstein. 1970. Lymphosarcoma: virus-induced thymic independent disease in mice. Cancer Res. 30:2213-2222.

2. Bonner, W. M., and R. A. Laskey. 1974. A film detection method for tritium-labeled proteins and nucleic acids in polyacrylamide gels. Eur. J. Biochem. 46:83-88.

3. Brugge, J. S., and R. L. Erikson. 1977. Identification of a transformation-specific antigen induced by an avian sarcoma virus. Nature (London) 269:346-347.

4. Deppart, W., and R. Pates. 1979. Simian virus 40 specific proteins on surface of HeLa cells infected with adenovirus $2-\mathrm{SV} 40$ hybrid virus Ad2 ${ }^{+} \mathrm{ND} 2$. Nature (London) 277:322-323.

5. Graf, T., and H. Beug. 1978. Avian leukemia viruses: interaction with their target cells in vivo and in vitro. Biochim. Biophys. Acta 516:269-300.

6. Kennel, S. J., B. Del Villano, R. Levy, and R. A. Lerner. 1973. Properties of an oncornavirus glycoprotein: evidence for its presence on the surface of virions and infected cells. Virology 55:464-475. 
7. Kessler, S. W. 1975. Isolation of antigens from cells with a staphylococcal protein-A-antibody adsorbent: parameters of the interaction of antibody-antigen complexes with protein A. J. Immunol. 115:1617-1624.

8. Laemmli, U. K. 1970. Cleavage of structural proteins during the assembly of the head of bacteriophage T4. Nature (London) 227:680-685.

9. Potter, M., M. D. Sklar, and W. P. Rowe. 1973. Rapid viral induction of plasmocytomas in pristane-primed BALB/c mice. Science 182:592-594.

10. Pratt, D. M., J. Strominger, R. Parkman, D. Kaplan, J. Schwaber, N. Rosenberg, and C. D. Scher. 1977. Abelson virus transformed lymphocytes: null cells that modulate H-2. Cell 12:683-690.

11. Premkumar, E., M. Potter, P. A. Singer, and M. D. Sklar. 1975. Synthesis, surface deposition and secretion of immunoglobulins by Abelson virus transformed lymphosarcoma cell lines. Cell 6:149-159.

12. Purchio, A. F., E. Erikson, J. S. Brugge, and R. L. Erikson. 1978. Identification of a polypeptide encoded by the avian sarcoma virus src gene. Proc. Natl. Acad. Sci. U.S.A. 75:1567-1571.

13. Raschke, W. C., S. Baird, P. Ralph, and I. Nakoinz. 1978. Functional macrophage cell lines transformed by Abelson leukemia virus. Cell 15:261-267.

14. Reynolds, F. H., T. L. Sacks, D. N. Deobaghar, and J. R. Stephenson. 1978. Cells nonproductively transformed by Abelson murine leukemia virus express a high molecular weight polyprotein containing structural and non-structural components. Proc. Natl. Acad. Sci. U.S.A. 75:3974-3978.

15. Risser, R., M. Potter, and W. P. Rowe. 1978. Abelson virus-induced lymphomagenesis in mice. J. Exp. Med. 148:714-726.

16. Risser, R., E. Stockert, and L. J. Old. 1978. Abelson antigen: a viral tumor antigen that is also a differentiation antigen of BALB/c mice. Proc. Natl. Acad. Sci. U.S.A. 75:3918-3922.

17. Rosenberg, N., and D. Baltimore. 1978. The effect of helper virus on Abelson virus-induced transformation of lymphoid cells. J. Exp. Med. 147:1126-1141.

18. Rosenberg, N., D. Baltimore, and C. D. Scher. 1975. In vitro transformation of lymphoid cells by Abelson murine leukemia virus. Proc. Natl. Acad. Sci. U.S.A. 72:1932-1936.

19. Scher, C. D., and R. Siegler. 1975. Direct transformation of 3T3 cells by Abelson murine leukemia virus. Nature (London) 253:729-731.

20. Sherr, C. J., A. Sen, G. J. Todaro, A. Sliski, and M. Essex. 1978. Pseudotypes of feline sarcoma virus contain an 85,000 -dalton protein with feline oncornavirus associated cell membrane antigen (FOCMA) activity. Proc. Natl. Acad. Sci. U.S.A. 75:1505-1509.

21. Siden, E. J., D. Baltimore, N. Rosenberg, and D. Clark. 1979. Immunoglobulin synthesis by lymphoid cells transformed in vitro by Abelson murine leukemia virus. Cell 16:389-396.

22. Silverstone, A. E., N. Rosenberg, V. L. Sato, M. P. Scheid, E. A. Boyse, and D. Baltimore. 1978. Correlating terminal deoxynucleotidyl transferase and cell surface markers in the pathway of lymphocyte ontogeny, p. 433-453. In B. Clarkson, P. A. Marks, and J. E. Till (ed.), Differentiation of normal and neoplastic hematopoetic cells. Cold Spring Harbor Laboratory Press, Cold Spring Harbor, N.Y.

23. Sklar, M. D., E. M. Shevach, I. Green, and M. Potter. 1975. Transplantation and preliminary characterization of lymphocyte surface markers of Abelson virus-induced lymphomas. Nature (London) 253:550-552.

24. Stephenson, J. R., A. S. Khan, A. H. Sliski, and M. Essex. 1977. Feline oncornavirus cell membrane associated antigen: evidence for an immunological crossreactive feline sarcoma virus coded protein. Proc. Natl Acad. Sci. U.S.A. 74:5608-5612.

25. Tarentino, A. L., and F. Maley. 1974. Purification and properties of an endo- $\beta$ - $\mathrm{N}$-acetyl-glucosaminidase from Streptomyces griseus. J. Biol. Chem. 249:811-816.

26. Tung, J.-S., T. Yoshiki, and E. Fleissner. 1977. A core polyprotein of murine leukemia virus on the surface of mouse leukemia cells. Cell 9:573-578.

27. Van Zaane, D., and H. P. J. Bloemers. 1978. The genome of the mammalian sarcoma viruses. Biochim. Biophys. Acta 516:249-268.

28. Witte, O. N., and D. Baltimore. 1978. Relationship of retrovirus polyprotein cleavages to virion maturation studied with temperature-sensitive murine leukemia virus mutants. J. Virol. 26:750-761.

29. Witte, O. N., N. Rosenberg, M. Paskind, A. Shields, and D. Baltimore. 1978. Identification of an Abelson murine leukemia virus-encoded protein present in transformed fibroblast and lymphoid cells. Proc. Natl. Acad. Sci. U.S.A. 75:2488-2492.

30. Witte, O. N., and I. L. Weissman. 1976. Oncornavirus budding: kinetics of formation and utilization of viral membrane glycoprotein. Virology 69:464-473.

31. Witte, O. N., I. L. Weissman, and H. S. Kaplan. 1973 Structural characteristics of some murine RNA tumor viruses studied by lactoperoxidase iodination. Proc. Natl. Acad. Sci. U.S.A. 70:36-40.

32. Witte, O. N., and D. Wirth. 1979. Structure of the murine leukemia virus envelope glycoprotein precursor. J. Virol. 29:735-743. 